\title{
Oral hygiene practice and periodontal status among two tribal population of Telangana state, India- an epidemiological study
}

\author{
Shaik Mohammed Asif ${ }^{* *}$ (D), Shaik Naheeda ${ }^{2}$, Khalil Ibrahim Assiri ${ }^{3}$, Hussain Mohammed Almubarak³,
} Sultan Mohammed Kaleem ${ }^{3}$, M. Zakirulla ${ }^{4}$, Fawaz Abdul Hamid Baig ${ }^{5}$ and Mohammed Zahir Kota ${ }^{5}$

\begin{abstract}
Background: The tribes of India have poor periodontal health status due to their isolation, awareness and less accessibility to dental resources. They follow traditional methods of oral hygiene practice, which are found to be inadequate and inaccurate to maintain their good oral health. This study aims to assess the oral hygiene practice, oral hygiene and periodontal status of two tribes residing in Bhadrachalam, Telangana, India.

Methods: Based on accessibility the two tribes Koya and Lambada were included in the study. The total study population consisted of 1000 subjects, with 500 subjects in each group. Using a preformed proforma the oral hygiene practices were recorded for two groups and oral examination was done using Oral Hygiene Index (OHI-S) index and Community Periodontal Index (CPI).

Results: The OHI-S ranged between 2.5-3.0 in both the groups. The CPI index scores showed that sextants with calculus, shallow pockets, deep pockets and loss of attachment of $4-5 \mathrm{~mm}$ were significantly present in both groups.

Conclusion: To conclude, though practice of poor oral hygiene and compromised periodontal status was seen among both groups. However, it was more prevalent in Koya. Under these circumstances, implementation of a basic awareness of oral health care programme for these tribes should be a high priority.
\end{abstract}

Keywords: Tribes, Periodontal disease, Community periodontal index, Oral hygiene index- simplified

\section{Background}

Various research have designated that, periodontal disease are as ancient as mankind. It could be due to difference in life style and oral hygiene habits [1]. Though efforts have been put fighting against periodontal disease, problem still persist among poor and socially marginalized communities. The situation is particularly severe in developing countries like India [2]. In this modern era, there are people who are living in isolation in natural and unpolluted surrounding far away from civilization with their traditional values, customs, beliefs and myths. They are known as "tribes," for which India is a homeland providing shelter for 75 of such

\footnotetext{
* Correspondence: masif020@gmail.com

'Department of Diagnostic Science \& Oral Biology, College of Dentistry, King Khalid University, Abha, Kingdom of Saudi Arabia

Full list of author information is available at the end of the article
}

tribal communities [2]. The primitive tribal communities have been identified by government of India in 15 states/ union territories on basis of pre agricultural level of technology, extremely low level of literacy; and small stagnant or diminishing population [3]. The only south Indian state with tribal population of $9.34 \%$ is Telangana out of its total population as per 2011 census [3]. However, most of these tribes are found inhabiting in higher concentration in districts of north and northeastern parts of State. In Telangana, Khammam district has largest tribal population. Koyas and Lambadas are the major tribes leaving in the ITDA (Integrated Tribal Development Agency) of Bhadrachalam [4]. Koyas due to their low annual income and lack of land ownership they work as daily farm laborers [5]. Lambadas live in settlements referred as Thanda $[5,6]$. They are more civilized when compared to Koyas [6].

(c) The Author(s). 2019 Open Access This article is distributed under the terms of the Creative Commons Attribution 4.0 International License (http://creativecommons.org/licenses/by/4.0/), which permits unrestricted use, distribution, and reproduction in any medium, provided you give appropriate credit to the original author(s) and the source, provide a link to the Creative Commons license, and indicate if changes were made. The Creative Commons Public Domain Dedication waiver (http://creativecommons.org/publicdomain/zero/1.0/) applies to the data made available in this article, unless otherwise stated. 
Research has shown that low socioeconomic and ethnic minority groups are less likely to utilize health service [7]. Hence, evaluation of oral health in these communities is an important part for deciding accurate and respectable health care. As there is no literature available, regarding oral health status of these population, this present study aimed to assess the oral hygiene practice and periodontal status of these two tribes inhabiting in Bhadrachalam division of Khammam district, Telangana, India.

\section{Methods}

It is a cross sectional epidemiological study conducted to assess the oral hygiene practice and periodontal status of two tribes residing in Bhadrachalam, Telangana, India. It has been systemically scheduled to spread over a period of two and half years (July 2015 to January 2018). Institutional review board of private dental college issued an ethical clearance and ITDA Officer of that area permitted to conduct the study. With guidance from ITDA office and help from dental auxiliaries of that region, it was made sure that eloquent number of samples were accessible during the day of examination. An informed consent verbally and a written declaration were obtained from participants after discussing in detail about the purpose of the study.

\section{Sample size collection}

A preliminary study was conducted to determine the sample size on the results obtained and to check for the feasibility of participants during the study. After conducting the pilot study the prevalence of periodontal disease was assessed and the sample size attained as follows: The prevalence of periodontal disease in I tribal group P1 $=$ $0.45 \%$ (Proportion in the I group P1 $=0.4520$ ) The prevalence of periodontal disease in II tribal group P2 $=0.56 \%$ (Proportion in the II group P2 $=0.5656$ ) Risk difference $(\mathrm{P} 1-\mathrm{P} 2)=-0.1136$ Power of test $(\%)=95$ Alpha Error $(\%)=$ $5 \mathrm{n}=[(\mathrm{Z} \alpha / 2+\mathrm{Z} \beta) 2 \times\{(\mathrm{p} 1(1-\mathrm{p} 1)+(\mathrm{p} 2(1-\mathrm{p} 2))\}] /(\mathrm{p} 1-\mathrm{p} 2) 2$ $\mathrm{p} 1=$ Proportion in the first population $\mathrm{p} 2=$ Proportion in the second population $\alpha=$ Significance level $\beta=$ Power of test $Z \alpha=(1.96)$ Table value $Z \beta=(1.682)$ Table value Sample size $n=500$ in each group. Hence, total sample size was thousand. We used a modified WHO proforma which had queries related to oral hygiene practice that might have indirectly affected on Periodontium and its supporting structures [8]. To ascertain the prevalence of periodontal disease and the attachment loss CPI index was used (Jukka Ainamo, David Barmes, George Beagrie (1994) [8].

\section{Inclusion criteria}

Subjects willing to participate in the age group of (20 to 75 years), and those who were present during the day of examination were included in the study.

\section{Exclusion criteria}

Children, edentulous patients and those subjects who were absent or not willing to participate in the study were excluded.

Oral examination was conducted in regional hospital of Bhadrachalam Mandal for the Koya group and Pichakalapadu Village for the Lambada group. Intra- examiner variability, was reviewed by department staff of Periodontics, private dental College to reduce intra-examiner variability before conducting the pilot study. Autoclave method was used to sterilize the instruments in sterilization section of the area hospital, Bhadrachalam. If needed chemical sterilizer was used before oral examination. For collection of data, a specially designed pre tested proforma was used. The proforma consists of three parts. The first part was questions related to demographic data such as age, gender, occupation and address. The second part of questions were related to oral hygiene practice. The third part of the questionnaire was clinical examination of the subjects using OHI-S and CPI indices (Greene \& Vermillion - 1964) [8, 9]. The observed results were analyzed using Statistical Package for Social Science (SPSS 20) by IBM. Chi- Square test was used to determine the distribution of study samples by type of tribal population and various parameters such as age, gender, occupation, oral hygiene practices. Kruskal Wallis Anova and Mann- Whitney U test was used to compare the two tribal population with respect to OHI-S index and CPI index. $P<0.05$ was considered statistically significant.

\section{Results}

The study population was of 1000 , with 500 subjects from each group. As per results of present study, the mean age of subjects in Koya and Lambada groups was $40.52 \pm$ 14.69 and $39.34 \pm 13.77$ years. Majority of participants were females (Table.1). A statistically significant difference $(p<0.05)$ was observed with respect to occupation among these two tribes. In Koya group most of the participants were farmers (69\%) and mainly cultivated tobacco $23.4 \%$ were daily labors (Table 2). The occupation of Lambada group was business (65\%) followed by daily wage labors and farmers (Table 2). In Koya group 37.40\% used twigs to clean their teeth, $32.6 \%$ used tooth brush and $17.6 \%$ used finger to clean their teeth (Table 3). However, in Lambada group $46.4 \%$ used tooth brush, 30\% used twig and only 9.4\% used finger to clean their teeth (Table 3). In Koya

Table 1 Distribution of gender of tribal population

\begin{tabular}{lllll}
\hline Gender & Koya & $\%$ & Lambada & $\%$ \\
\hline Male & 215 & 43.00 & 222 & 44.40 \\
Female & 285 & 57.00 & 278 & 55.60 \\
Total & 500 & 100.00 & 500 & 100.00 \\
\hline
\end{tabular}

Chi-square $=0.4270, \mathrm{df}=2, p=0.8076$ 
Table 2 Distribution of Occupation of Both Tribes

\begin{tabular}{lllll}
\hline Occupation & Koya & $\%$ & Lambada & $\%$ \\
\hline Agriculture & 345 & 69.00 & 52 & 10.40 \\
Business & 10 & 2.00 & 325 & 65.00 \\
Coolie & 117 & 23.40 & 94 & 18.80 \\
Housewife & 28 & 5.60 & 12 & 2.40 \\
Others & 0 & 0.00 & 17 & 3.40 \\
Total & 500 & 100.00 & 500 & 100.00 \\
\hline $\begin{array}{l}\text { Chi-square }=293.5892, \mathrm{df}=8, p=0.00001^{*} \\
* P<0.05\end{array}$ & & &
\end{tabular}

$36.8 \%$ did not use any material for cleaning their teeth and only $22 \%$ used tooth powder for cleaning their teeth (Table 4). In Lambada group $30.8 \%$ used tooth paste, $29.4 \%$ did not use any material and $25.8 \%$ used sand and others as material for cleaning their teeth (Table 4). In Koya group, $64 \%$ of them were not sure of using any particular type of toothbrush ands only $13.6 \%$ of them were using soft tooth brush. $73.2 \%$ of Koya group and $74 \%$ of Lambada group cleaned their teeth in horizontal direction followed by a combination of horizontal and vertical method (Table 5). All these participants brushed their teeth once daily and mostly before meals in the early morning. A significant difference was observed with frequencies of change of brush in two tribal group $(p<0.05)$ $63 \%$ of Koya group and $51.2 \%$ of Lambada group never changed their brush. Only $31.80 \%$ of participants of Koya group changed their brush once in 3 months. Where as in Lambada group, $46.00 \%$ of them changed their brush once in 3 months (Table 6). 51.2\% of Koya group and $63.4 \%$ of Lambada group rinse their mouth after every meal (Table 6). The mean Debris Index simplified (D.I) were $1.20 \pm 0.43$ for Lambada and $1.24 \pm 0.42$ for Koya group which was statistically significant (Table 7). The mean calculus Index simplified (C.I) were $1.33 \pm$ 0.61 for Lambada and $1.35 \pm 0.49$ for the Lambada group which was statistically significant (Table 7 ). The mean OHI-S index values for Koya and Lambada group were $2.56 \pm 0.82$ and $2.51 \pm 0.93$ (Table 7). The mean number of sextants affected by periodontal disease according to CPI Index in Koya group for

Table 3 Distribution of type of cleaning aid used among both tribes

\begin{tabular}{lllll}
\hline Type of cleaning & Koya & $\%$ & Lambada & $\%$ \\
\hline Tooth brush & 163 & 32.60 & 232 & 46.40 \\
Finger & 88 & 17.60 & 47 & 9.40 \\
Twig & 187 & 37.40 & 150 & 30.00 \\
Combinations & 62 & 12.40 & 71 & 14.20 \\
Total & 500 & 100.00 & 500 & 100.00 \\
\hline
\end{tabular}

Chi-square $=540.6722, \mathrm{df}=6, p=0.00001^{*}$

${ }^{*} \mathrm{P}<0.05$
Table 4 Distribution of Materials used for cleaning by both tribes

\begin{tabular}{lllll}
\hline Materials used for cleaning & Koya & $\%$ & Lambada & $\%$ \\
\hline None & 184 & 36.80 & 147 & 29.40 \\
Tooth Paste & 110 & 22.00 & 154 & 30.80 \\
Tooth Powder & 5 & 1.00 & 0 & 0.00 \\
Charcoal & 66 & 13.20 & 74 & 14.80 \\
Sand and others & 135 & 27.00 & 125 & 25.00 \\
Total & 500 & 100.00 & 500 & 100.0 \\
\hline
\end{tabular}

Chi-square $=496.642, \mathrm{df}=8, p=0.00001^{*}$ ${ }^{*} P<0.05$

bleeding on probing was $0.51 \pm 0.81$ and in Lambada group it was $0.42 \pm 0.68$ which was statistically significant (Table 8). The mean calculus in Koya group was $4.11 \pm 1.46$ and in Lambada group it was $4.37 \pm 1.29$ which was statistically significant (Table 8). Among periodontal conditions, calculus was more prevalent in both groups followed by shallow pockets i.e., Pockets measuring 4-5 mm. (Table 8). In comparison of two tribal population for mean number of sextants affected with periodontal disease according to loss of attachment component of CPI Index (Table 9) shows that, very few sextants in both groups showed loss of attachment of $\geq 6 \mathrm{~mm}$. None of the participants in either of the group showed loss of attachment $\geq 12 \mathrm{~mm}$. (Table 9).

\section{Discussion}

This study aims to assess the oral hygiene practice, oral hygiene and periodontal status of two tribes residing in Bhadrachalam, Telangana, India. Primitive tribal communities have been identified by the Government of India based on their pre agricultural level of technology, extremely low level of literacy and small, stagnant or diminishing population [3, 7]. Major participants in the study were females. Similar findings were noticed among Nilgiris [1] tribes where participation of females (58\%) was more compared to males. This could be attributed to their esthetic concerned and co-operative nature of females [1]. The

Table 5 Distribution of Method of cleaning among both tribes

\begin{tabular}{lllll}
\hline Methods of cleaning & Koya & $\%$ & Lambada & $\%$ \\
\hline Vertical & 17 & 3.40 & 10 & 2.00 \\
Horizontal & 366 & 73.20 & 370 & 74.00 \\
Circular & 1 & 0.20 & 0 & 0.00 \\
Vertical and Horizontal & 77 & 15.40 & 100 & 20.00 \\
Horizontal and Circular & 39 & 7.80 & 20 & 4.00 \\
Total & 500 & 100.00 & 500 & 100.00 \\
\hline
\end{tabular}

Chi-square $=81.5732, \mathrm{df}=8, p=0.00001^{*}$

${ }^{*} P<0.05$ 
Table 6 Distribution of frequency of Brushing, Frequency of Change of brush, and Rinsing of mouth after meals by both tribes

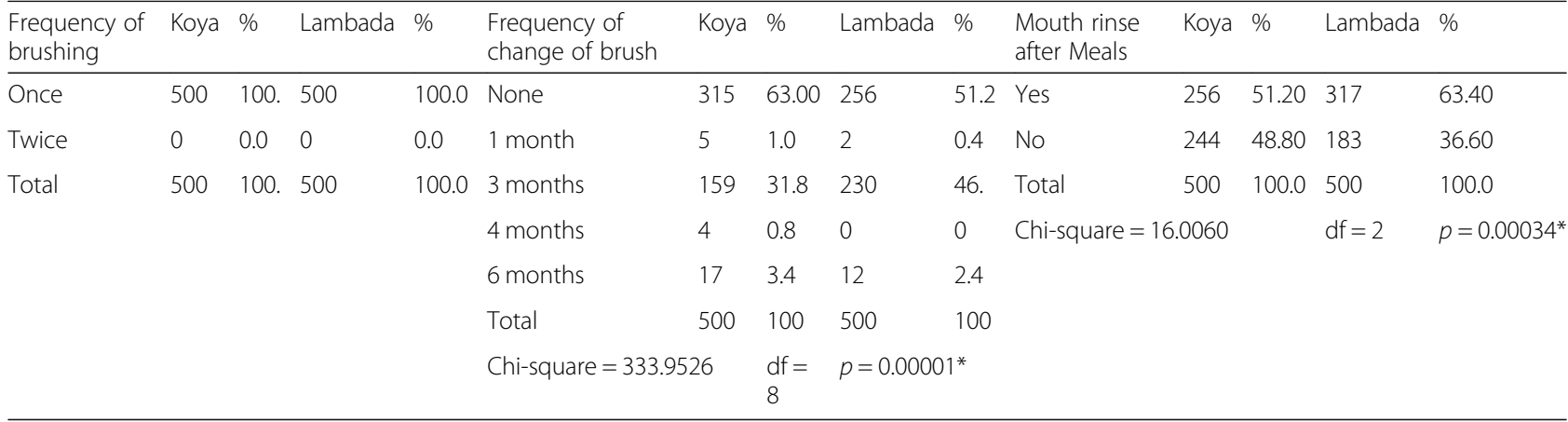

${ }^{*} p<0.05$

occupation of major participants in Lambada group was Business $(65 \%)$ followed by daily wage laborers and farmers as they are more civilized and have better communication with modern society through transport and most of them were into business as their occupation. Majority of Koyas used twig as their regular oral hygiene method and Lambadas used tooth brush as their cleansing aid. Similar findings were noticed by Jordan RA [10] in rural population of Gambia in West Africa, where majority of the population used chew sticks (50.6\%) followed by toothbrush (34.6\%). Similarly Padma BK et al. [11] reported that chew sticks were commonly used than toothbrushes as an oral hygiene aid among Iruliga tribes in Karnataka, India. Contrastingly, Khadir et al. [12] who conducted a study in aborigines of Selangor, West Malaysia reported that majority of the population used toothbrush with toothpaste and they brushed their teeth once daily. The authors suggested that these responses from the participants could have been influenced by factors such as desirability of participants to answer questions on dental health and behavior in a socially desirable way [12]. The mean OHI-S index [9] values for Koya and Lambada indicated a fair oral hygiene status. The present findings are in accordance with similar studies conducted on other communities like Australian Aborigines [13], residents of Kolar district [14] and municipal employees of Mysore [15]. The high mean values of the oral hygiene index and its components suggest a widespread and uniform neglect of tooth cleaning/ brushing habit among tribal groups [1]. The average number of sextants with healthy condition in present study and sextants with Bleeding on probing were significantly less in Koya and Lambada groups. Similar findings were noticed by Jordan et al. [10] in rural African Gambia population. The authors proposed that use of two tooth cleaning aids i.e., twigs and toothbrush lead to decrease gingival inflammation [10]. Sextants with calculus, shallow pockets and deep pockets were high in Koya and Lambada groups. Among all the periodontal condition, Koya's had least calculus when compared to Lambadas. This is due to the fact that, the people belonging to this tribe consume large amounts of vegetables, tubers and roots, which may have a self-cleansing effect on the teeth [16]. The diet also plays a role in maintaining their oral hygiene as the diet of Koya tribe includes highly abrasive food while excluding those consisting mostly of refined carbohydrates [16]. Periodontitis of any form was less prevalent in Lambada tribe it is due to their awareness about oral health owing to their communication with modern society for the purpose of trade.

Table 7 Minimum, maximum, mean and SD of Debris index, calculus and OHIS scores of two tribal populations

\begin{tabular}{|c|c|c|c|c|c|c|c|c|c|}
\hline \multirow[t]{2}{*}{ Tribes } & \multicolumn{3}{|c|}{ Debris Index (DI) } & \multicolumn{3}{|c|}{ Calculus Index (Cl) } & \multicolumn{3}{|l|}{$\mathrm{OHI} \mathrm{S}$} \\
\hline & Mean & SD & Sum of ranks & Mean & SD & Sum of ranks & Mean & SD & Sum of ranks \\
\hline Lambada & 1.20 & 0.43 & 334,815 & 1.33 & 0.61 & 337,490 & 2.51 & 0.93 & 334,915 \\
\hline Koya & 1.24 & 0.42 & 352,120 & 1.35 & 0.49 & 349,945 & 2.56 & 0.82 & 347,625 \\
\hline$P$-value & & $0.00001^{*}$ & & & $0.00001^{*}$ & & & $0.00001^{*}$ & \\
\hline \multicolumn{10}{|c|}{$\begin{array}{l}\text { Pair wise comparison of both } \\
\text { tribal populations by } \\
\text { Mann-Whitney U test }\end{array}$} \\
\hline Koya vs Lambada & & 0.1903 & & & 0.2724 & & & 0.2545 & \\
\hline
\end{tabular}


Table 8 Comparison of two tribal population for - Mean number of sextants affected by periodontal disease condition according to CPI index

\begin{tabular}{|c|c|c|c|c|c|c|}
\hline \multirow[t]{2}{*}{ Variables } & & \multicolumn{2}{|c|}{ Tribes } & \multirow[t]{2}{*}{$\mathrm{H}$-value } & \multirow[t]{2}{*}{$P$-value } & \multirow{2}{*}{$\begin{array}{l}\text { Pair wise comparison } \\
\text { Koya vs Lambada }\end{array}$} \\
\hline & & Koya & Lambada & & & \\
\hline \multirow[t]{2}{*}{ Healthy } & Mean & 0.57 & 0.49 & 150.17 & $0.00001^{*}$ & 0.35 \\
\hline & SD & 0.98 & 0.89 & & & \\
\hline \multirow[t]{2}{*}{ Bleeding } & Mean & 0.51 & 0.42 & 54.89 & $0.00001^{*}$ & 0.29 \\
\hline & SD & 0.81 & 0.68 & & & \\
\hline \multirow[t]{2}{*}{ Calculus } & Mean & 4.11 & 4.37 & 43.69 & $0.00001^{*}$ & 0.015 \\
\hline & SD & 1.46 & 1.29 & & & \\
\hline \multirow[t]{2}{*}{ Pocket (4-5 mm) } & Mean & 0.51 & 0.58 & 73.85 & $0.00001^{*}$ & 0.090 \\
\hline & SD & 0.82 & 0.83 & & & \\
\hline \multirow[t]{2}{*}{ Pocket (6 mm or more) } & Mean & 0.01 & 0.01 & 2.84 & 0.2420 & 0.96 \\
\hline & SD & 0.09 & 0.08 & & & \\
\hline \multirow[t]{2}{*}{ Excluded sextants } & Mean & 0.01 & 0.01 & 2.43 & 0.2130 & 0.87 \\
\hline & SD & 0.08 & 0.08 & & & \\
\hline \multirow[t]{2}{*}{ Total } & Mean & 1.74 & 1.82 & 134.69 & $0.00001^{*}$ & $0.01^{*}$ \\
\hline & SD & 0.48 & 0.44 & & & \\
\hline
\end{tabular}

${ }^{*} p<0.05$ by Kruskal Wallis ANOVA and Mann-Whiney $\mathrm{U}$ test

\section{Conclusion}

Lambadas had better oral hygiene practice. Poor oral hygiene status and periodontitis was more prevalent among Koyas which could be related to their lack of knowledge regarding the dental care. There is a consensus agreement that periodontal health status of tribal population is very poor and worst among primitive tribes because of their isolation, remoteness therefore, dental resources should be made easily accessible. Ethnic believes which inhibit the use of health care services can be overcome by motivating, training primary health care workers who are in continuous contact with these tribes. This can help bridge the gap between oral health practice and oral health needs of tribes. Hence, community based approach for promotion of good oral hygiene should be carried out among these tribes on a large scale for control and prevention periodontal disease.

Table 9 Comparison of two tribal populations for - Mean number of sextants affected with periodontal disease according to Loss of Attachment component of CPI index

\begin{tabular}{|c|c|c|c|c|c|c|}
\hline \multirow[t]{2}{*}{ Variables } & & \multicolumn{2}{|c|}{ Tribes } & \multirow[t]{2}{*}{$\mathrm{H}$-value } & \multirow[t]{2}{*}{$P$-value } & \multirow{2}{*}{$\begin{array}{l}\text { Pair wise comparison } \\
\text { Koya vs Lambada }\end{array}$} \\
\hline & & Koya & Lambada & & & \\
\hline \multirow[t]{2}{*}{ Score -0} & Mean & 4.03 & 3.83 & 57.3970 & $0.00001^{*}$ & 0.0812 \\
\hline & SD & 1.95 & 1.89 & & & \\
\hline \multirow[t]{2}{*}{ Score - 1} & Mean & 1.37 & 1.75 & 86.6340 & $0.00001^{*}$ & $0.0003^{*}$ \\
\hline & SD & 1.49 & 1.55 & & & \\
\hline \multirow[t]{2}{*}{ Score -2} & Mean & 0.29 & 0.27 & 7.7850 & $0.0200^{*}$ & 0.9999 \\
\hline & SD & 0.74 & 0.70 & & & \\
\hline \multirow[t]{2}{*}{ Score -3} & Mean & 0.05 & 0.01 & 10.7910 & $0.0050^{*}$ & 0.5460 \\
\hline & SD & 0.31 & 0.14 & & & \\
\hline \multirow[t]{2}{*}{ Score -4} & Mean & 0.00 & 0.00 & 0.0000 & 1.0000 & 1.0000 \\
\hline & SD & 0.00 & 0.00 & & & \\
\hline \multirow[t]{2}{*}{ Excluded sextants } & Mean & 0.01 & 0.01 & 2.43 & 0.2130 & 0.87 \\
\hline & SD & 0.08 & 0.08 & & & \\
\hline \multirow[t]{2}{*}{ Total } & Mean & 0.38 & 0.40 & 56.6280 & $0.00001^{*}$ & 0.0537 \\
\hline & SD & 0.46 & 0.40 & & & \\
\hline
\end{tabular}

${ }^{*} p<0.05$ by Kruskal Wallis ANOVA and Mann-Whiney $\mathrm{U}$ test 


\section{Abbreviations}

C.I: Calculus Index Simplified; CPI: Community Periodontal Index; D.I: Debris Index Simplified; ITDA: Integrated Tribal Development Agency; OHI-S index: Oral Hygiene Index; WHO: World Health Organization

\section{Acknowledgements}

The authors would like to acknowledge the ITDA officer and the dental auxiliaries who helped during the entire study.

\section{Funding}

None.

\section{Availability of data and materials}

The datasets generated and analyzed during the current study are available from the corresponding author on reasonable request.

\section{Authors' contributions}

SN \& SMA contributed to concept and design of the study. KA \& HM conducted and documented OHIS \& CPI. SM K \& ZM documented the manuscript and revised it critically for important intellectual content. FAB \& MZK revised and edited the manuscript gave final approval for the version to be published. All authors agreed to be accountable of the work.

\section{Ethics approval and consent to participate}

The protocol of this study was approved by institutional review board of Mamata Dental College (SRC/EH/2015-16/09). Informed consent to participate was obtained from all participants.

\section{Consent for publication}

Not applicable.

\section{Competing interests}

The authors declare that they have no competing interests.

\section{Publisher's Note}

Springer Nature remains neutral with regard to jurisdictional claims in published maps and institutional affiliations.

\section{Author details}

'Department of Diagnostic Science \& Oral Biology, College of Dentistry, King Khalid University, Abha, Kingdom of Saudi Arabia. ${ }^{2}$ Department of Periodontology, Guardian College of Dental Science and Research Centre, Ambernath, Thane, India. ${ }^{3}$ Department of Diagnostic Sciences \& Oral Biology, College of Dentistry, King Khalid University, Abha, Kingdom of Saudi Arabia. ${ }^{4}$ Department of Pediatric Dentistry \& Orthodontic Sciences, College of Dentistry, King Khalid University, Abha, Kingdom of Saudi Arabia. ${ }^{5}$ Department of Maxillofacial Diagnostic science, College of Dentistry, King Khalid University, Abha, Kingdom of Saudi Arabia.

Received: 5 September 2018 Accepted: 26 December 2018

Published online: 09 January 2019

\section{References}

1. Philip B, Chithresan K, Vijayaragavan VS, Maradi A. Prevalence of periodontal diseases among the adult tribal population in Nilgiris - an epidemiological study. Int J Pub Health Dent. 2013:4:8-12.

2. Grewal Y, Datta R, Singh K, Singh G, Singh S, Kaur P. Prevalence of periodontal disease in the rural population of Punjab. J Pharm Biomed Sci. 2014:4:532-5.

3. Chandra Shekar BR, Raja BP. Cultural factors in health and oral health. Indian Journal of Dental Advancement. 2009:1:24-30.

4. Laxmaiah A, Mallikharjuna KR, Hari Kumar R, Arlappa N, Venkaiah K, Brahmam GNV. Diet and nutritional status of tribal population in ITDA project areas of Khammam District, Andhra Pradesh. J Hum Ecol. 2007:21:79-86.

5. Satya ND. Tribes of Telangana: society, Religion and Culture, Hyderabad. Telangana Resource centre. 2014:p23-4.

6. Satya ND. Tribes of Telangana: society, Religion and Culture, Hyderabad. Telangana Resource centre. 2014:p30-1.

7. Sekhon TS, Grewal S, Gambhir RS. Periodontal health status and treatment needs of the rural population of India: a cross-sectional study. J Nat SciBiol Med. 2015;6:111-5.
8. Ainamo J, Barmes D, Beagrie G, Cutress T, Martin J, Sardo-Infirri J. Development of the World Health Organization (WHO) community periodontal index of treatment needs (CPITN). Int Dent J. 1982;32(3):281-91.

9. Greene JC, Vermillion JR. The simplified oral hygiene index. J Am Dent Assoc. 1964;68(1):7-13.

10. Jordan RA, Lucaciu A, Fotouhi K, Markovic L, Gaengler P, Zimmer S. Pilot pathfinder survey of oral hygiene and periodontal conditions in the rural population of the Gambia (West Africa). Int J Dent Hyg. 2011;9:53-9.

11. Padma BK, Sushi K. Periodontal health status and oral hygiene practices of Iruliga tribal community residing at Ramnagar district, Karnataka. India J Int Oral Health. 2010;2:17-26.

12. Kadir RA, Yassin AT. Oral health beliefs, practice and attitudes towards dental health among the aborigines (orang asli) of Selangor, West Malaysia. Tropical Dent J. 1989;12:7-12.

13. Sehamschula RG, Cooper MH, Wright MC, Agus HM, UN PSH. Oral health of adolescent and adult Australian aborigines. Commu Dent Oral Epidemiol. 1980;8:370-4.

14. Megala manegowdru J, Ankola AV, Vathar J, Vishwakarma P, Dhanappa KB, Balappanavar AY. Periodontal health status among permanent residents of low, optimum and high fluoride areas in Kolar District, India. Oral Health Prev Dent. 2012;10:175-83.

15. Chandra Shekar BR, Reddy C. Oral health status in relation to socioeconomic factors among the municipal employees of Mysore city. Indian J Dent Res. 2011;22:410-8

16. Mehta R, Kundu D, Chakrabarty S, Bharati P. Periodontal conditions and treatment in urban and rural population of West Bengal, India. Asian Pac $J$ Trop Med. 2010;3:152-7.
Ready to submit your research? Choose BMC and benefit from:

- fast, convenient online submission

- thorough peer review by experienced researchers in your field

- rapid publication on acceptance

- support for research data, including large and complex data types

- gold Open Access which fosters wider collaboration and increased citations

- maximum visibility for your research: over $100 \mathrm{M}$ website views per year

At BMC, research is always in progress.

Learn more biomedcentral.com/submissions 